a small conductivity with increasing temperature, an increase in the temperature-range of bleaching and the maintenance of this increased conductivity on cooling.

Mr. J. Ewles (Leeds) gave an account of investigations, recently completed at Leeds, into the optical and electrical properties of phosphors. He pointed out that luminescence is not a rare phenomenon in solids but is likely to accompany imperfections in crystals whether these are caused by impurities or by thermal treatment. It is, in fact, rarely absent in real crystals, being suppressed only with extraordinary purity and in the absence of thermal strains. It can be intensified by sudden quenching, and reduced or removed by annealing. Recent experiments carried out by Lee have led to a modification of the theory of the large centre first introduced by Ewles in 1930. The modified theory now takes into account the competition of structure centres provided by imperfections, and is in good agreement with experiment. Further, it permits the evaluation of the size of the centre. Mr. Ewles also gave a brief account of the remarkable optical and electrical properties of some new oxygen-activated alkali halide phosphors investigated by Barmby. These phosphors show sharply resolved luminescent bands which must be attributed to oxygen ions adsorbed on the halide. The luminescence is accompanied by very large increases in conductivity. Thermoelectric powers up to some two millivolts per degree indicate that the conduction is electronic, and an interpretation in terms of the effect of the adsorbed oxygen on the band levels of the halide crystals was given.

In the section on ferroelectricity, two papers were presented : the first, by Dr. L. F. Cross, on ferroelectricity in the perovskite type structures; and the second, on the theory of ferroelectrics, by Dr. A. F. Devonshire.

Dr. Cross (Leeds) directed attention to the importance of accurate measurement of electric hysteresis in the ferroelectric state. He described the method normally used for measuring the hysteresis, and examined the limitation imposed by the electric conduction through the ferroelectric. After a brief description of the perovskite structure, he listed the minerals which are of interest electrically and, from them, examined in more detail barium titanate, potassium niobate and sodium niobate. The sequence of symmetry changes which occurs on cooling barium titanate was described by Dr. Cross, and the electric domain structures occurring in the tetragonal room-temperature phase examined, new evidence being produced to confirm the existence of a system of anti-parallel domains within the individual twin unit. Hysteresis figures obtained on untwinned barium titanate crystals above the ferroelectric Curie temperature were shown, and these were compared with previous results in the United States. New measurements of electric hysteresis effects in potassium and sodium niobates were also reported. In the potassium salt, the results were shown to be in reasonable agreement with previous work. Preliminary results on sodium niobate, however, have revealed a linear dielectric up to field-strengths of $20 \mathrm{kV} . / \mathrm{cm}$., and clearly this is not a normal ferroelectric.

Dr. Devonshire (Bristol) said that he would consider only the theory of the single domain. This theory can be divided into two parts: first, the purely thermodynamic theory of the relations of the elastic, piezoelectric and dielectric constants to each other; and second, the relation of these to the atomic structure. It is important to carry out a thermodynamical analysis of experimental results, before devising a detailed atomic theory. This analysis shows that all the anomalies observed at the transition temperature are due to the fact that the dielectric stiffness coefficient tends to zero at this point; Dr. Devonshire also suggested that the first-order character of the transition in barium titanate is probably due to the interaction between strain and polarization. The smallness of the dielectric stiffness coefficient is due largely to electrostatic interaction between the different parts of the polarized medium ; this is in contrast with ferromagnetic materials, for which magnetostatic interaction is of small importance. The temperature variation is due to the higher entropy of the unpolarized state. The existence of a lower transition in Rochelle salt is probably due to the existence of a stable anti-parallel arrangement of dipoles below this temperature.

The meeting provided a welcome opportunity for an exchange of views among those working in related fields, and full advantage was taken of this in a number of extended informal discussions.

\section{F. F. HOARE}

\section{OXIDATION OF OILS AND FATS}

A SYMPOSIUM on "Oxidation" was held by the Oils and Fats Group of the Society of Chemical Industry in the Low Temperature Research Station, Cambridge, on April 24. Prof. T. P. Hilditch, chairman of the Group, presided and welcomed some hundred-odd members and visitors. The programme was divided, after an introductory address, into two sessions of two papers each, one dealing mainly with the oxidative deterioration of fats and the other with the autoxidation of unsaturated fatty acids and esters and other topics related to drying oils and paints. Although the approach to, and aim of, this aspect of the problem are different, the chemical changes which take place have the same common basis, and for this reason the discussion on all the papers was taken together.

Prof. C. E. H. Bawn, in his introductory address, reviewed the fundamental ideas on the mechanism and chemistry of varied classes of organic molecules; for example, hydrocarbons (saturated, unsaturated, aromatic and hydro-aromatic), aldehydes and ketones, etc., which readily undergo autoxidation in the liquid or solution phase at relatively low temperatures. The radical chain theory of these processes has in recent years come to be widely accepted, and it is agreed that the initiation of the reaction requires the production of a free radical either by direct oxygen attack, photochemically or by an added agent. The reaction chain has been established to be of the following type :

$$
\begin{aligned}
\text { Initiation } & \rightarrow \text { free radical } R . \\
R+\mathrm{O}_{2} & \rightarrow R \mathrm{O}_{2} \\
R \mathrm{O}_{2}+R \mathrm{H} & \rightarrow R \mathrm{OOH}+R \\
R+R & \rightarrow \\
R+R \mathrm{O}_{2} & \rightarrow \text { inert products } \\
R \mathrm{O}_{2}+R \mathrm{O}_{2} & \rightarrow
\end{aligned}
$$

where $R \mathrm{H}=$ hydrocarbon, aldehydes, etc.

The initially formed hydroperoxide $(R \mathrm{OOH})$ is of varying stability, and at higher temperatures readily undergoes further decomposition. This decomposition is also a chain mechanism, and many examples. conform to the following type : 


$$
\begin{aligned}
R \mathrm{OOH} \rightarrow R \mathrm{O}+\mathrm{OH} \text { or } 2 R \mathrm{OOH} \rightarrow R \mathrm{O}_{2}+R \mathrm{O}+\mathrm{H}_{2} \mathrm{O} \\
R \mathrm{O}+R^{\prime} \mathrm{H} \rightarrow R \mathrm{OH}+R^{\prime} \\
R^{\prime}+R \mathrm{OOH} \rightarrow R^{\prime} \mathrm{OH}+R \mathrm{O} . \\
2 R^{\prime} \rightarrow \\
R^{\prime}+R \mathrm{O} \rightarrow \text { insctive products } \\
2 R \mathrm{O} \rightarrow
\end{aligned}
$$

where $R^{\prime} \mathrm{H}$ may be parent molecule $R \mathrm{H}$, solvent or added substrate. These secondary chain reactions, together with the direct thermal decomposition of the peroxide to saturated molecules and the decomposition of the radicals $R \mathrm{O}$ and $R \mathrm{O}_{2}$, give rise to the variety of products-aldehydes, ketones, alcohols, acids and esters-whieh usually appear when the oxidation is carried to any considerable extent. It is these reactions, to which all unsaturated organic compounds in particular are susceptible, which have important practical consequences, and, as will be seen from the papers discussed, they are responsible for the development of the rancidity of fats, the gelation of drying oils and also the deterioration of rubber and other high polymers.

It is well known that the salts of the heavy metals are good catalysts for autoxidation reactions, and these reactions are of great technical importance particularly in the field of drying oils and 'controlled' oxidation to form selective intermediates, such as the oxidation of aldehydes to acid anhydrides, cyclohexanol to adipic acid and isopropyl benzene to its hydroperoxide.

The point of view was expressed that these catalysts function essentially in the ionic form and that their activity resides in their ability to undergo electrontransfer reactions giving rise to free radicals: for example,

$$
\begin{aligned}
& \mathrm{Co}^{++}+\mathrm{ROOH} \rightarrow \mathrm{Co}^{+++}+\mathrm{RO}+\mathrm{OH}^{-} \\
& \mathrm{Co}+++2 \mathrm{OOH} \rightarrow \mathrm{Co}++\mathrm{RO}_{2}+\mathrm{H}^{+} .
\end{aligned}
$$

Prof. Bawn also referred to the profound effects of oxygen in polymerization mechanisms in which it may initiate and inhibit polymerization, and induce degradation, branching or cross-linking of polymer molecules according to conditions and environment.

In the opening paper of the first session, Dr. C. H. Lea reviewed some recent studies of the oxidative deterioration of edible lipoids. He said that the degradation products of the primarily formed hydroperoxide, particularly $\alpha \beta$ unsaturated aldehydes and ketones, are largely responsible for the unpleasant odour and flavour of oxidized fats. The relatively rapid autoxidation of poly-unsaturated acids compared with oleic acid emphasizes the deleterious effect of even small proportions of these acids in food fats. These substances not only increase the susceptibility of the whole fat to oxidation, but also the presence of acids containing three or more doublebonds seems to be the cause of the development of the characteristic 'off' flavour, usually described as 'reverted'. The actual mechanism by which these flavours are produced is not fully understood, but the consensus of opinion appears to be that they result from the oxidation of linolenic and more highly unsaturated fatty acids to a substance of unsaturated aldehydic and ketonic structure. Traces of copper and iron favour the development of flavour in fats, and quantities as low as a few parts per million produce appreciable effects in refined oils. In this respect the presence of chelating agents which inactivate trace metals has proved to be of considerable value in improving stability. The composition of animal fat, which is influenced by such factors as diet and rate of growth, affect the susceptibility to the development of oxidative rancidity. Dr. Lea discussed evidence from recent literature that peroxidized fat may be present in the tissues of still living animals which have been subjected to ionizing radiation. This problem is being mainly studied in the United States, and it has been observed that radiation initiates oxidative reactions in many foodstuffs with the consequent development of undesirable flavours. Dr. Lea also referred to the effect of enzymatic catalysts-the lipoxidases-which accelerate the peroxidation of unsaturated fats and fatty acids. These enzymes are very specific in their action towards different types of unsaturated groupings. In the United States much work has been done on antioxidants, and these are used extensively in fats and fat-containing materials. In Britain the whole question of the addition of antioxidants to food, like that of other non-nutrient chemicals, is still under consideration.

In the second paper Dr. Banks described some observations on the autoxidation of linoleic acid. $\mathrm{He}$ concluded that the produot is a mixture of peroxides, which cannot readily be separated; but after reduction and separation by partition between petrol ether and aqueous methanol two types of linoleic esters (hydroxy acids) are isolated. Investigations of the autoxidation of methyl linoleate in the presence of lauric and palmitic acids at $35^{\circ}$ and $55^{\circ} \mathrm{C}$. show that esterification does not occur at these temperatures, and this suggests that esters isolated are formed during reduction of the peroxides.

A review of recent work on the oxidation of monoethenoid fatty acids and their higher esters catalysed by metallic soaps (uranium, thorium, vanadium, etc.) was presented by Dr. Skellon. This work confirms that the primary product is a hydroperoxide which decomposes to give either epoxy, aldehydic, dehydroxy or keto-hydroxy derivatives. Oleic acid forms hydroperoxide only slowly at low temperatures, but at $85^{\circ}$ and $120^{\circ} \mathrm{C}$. this process is rapid, and the peroxide concentration passes through a well-defined maximum. Dihydroxy stearic acid, 10-hydroxy stearic acid, and small amounts of scission products have been isolated from the breakdown products of the hydroperoxide. Results were also given for the autoxidation of the trans isomer, ethyl, propyl and butyl esters of oleic acid, petroselenic acid, methyl recinoleate, and erucic and brassidic acids.

The drying of oil films and the manufacture of blown oils and linoleum gels are processes which depend on the formation of polymers by autoxidation. The results that have recently been obtained from extensive studies on these problems at the Paint Research Station were summarized by Dr. L. A. O'Neill. Evidence was presented in support of the view that one of the polymer-forming reactions in the autoxidation of non-conjugated drying oils results from the metallic salt-catalysed decomposition of the initially formed hydroperoxide. The main products obtained from the decomposition of the hydroperoxides of methyl linoleate and methyl linolenate are $-\mathrm{C}-\mathrm{C}$ bonded dimers which retain the full unsaturation of the original esters. Some unsaturation is lost in the process, and conjugated esters are formed by double-bond shift.

The products from the autoxidation of the conjugated drying oil-methyl elæostearate -are mainly monomeric peroxides (one of which has been isolated in the crystalline form) together with small amounts of polymeric peroxides which do not seem to be 
bonded by peroxide linkages. A tentative formula was proposed for the crystalline peroxide as

$\mathrm{CH} .\left(\mathrm{CH}_{2}\right)_{3} \cdot \mathrm{CH} . \mathrm{CH}=\mathrm{CH} . \mathrm{CH} \cdot \mathrm{CH}: \mathrm{CH}-$

Dr. O'Neill also described the results of direct studies of the autoxidation of drying oils in film form. Thus linseed oil takes up eight atoms of oxygen per molecule. Some of this oxygen is lost as volatile products, and only five atoms are retained after fourteen days. The volatiles include water, carbon dioxide, aldehydes and acid (particularly formic acid). Little change occurs in the film after a few days, and it seems necessary to postulate scission of the oxidation polymer in order to explain this high oxygen take-up.

C. E. H. BAwN

\section{SCIENCE AND GOVERNMENT}

$\mathrm{I}^{\mathrm{N}}$

his address, "Science and Government", to the American Chemical Society at its meeting in Los Angeles on March 16, Dr. L. A. DuBridge suggested that there are three points of contact between government and science. First, the nature, form and operation of the government determine the political, economic and intellectual climate of a nation, and whether the resulting climate is favourable to science or not may be accidental. If science is to flourish, however, that climate must provide for intellectual freedom, progressive change and the recognition and encouragement of intellectual pursuits. Secondly, science and its technological applications produce changes in the way men live, requiring corresponding changes in the operations, and possibly even in the forms of government. Advances in technology are a major source of advances in human welfare. Thirdly, science and government come together most directly and intimately when science affects matters such as national defence, agriculture, industry, transport, navigation, conservation of natural resources, flood control and the weather, which are prime functions of government.

Following this, Dr. DuBridge reviewed the gradual growth in the United States of government interest in science, from the establishment of the U.S. Coast Survey in 1807 and the creation of the Smithsonian Institution in 1846, until in 1952 Federal Government expenditure on research and development in science and technology was about 1,250 million dollars, or more than 40 per cent of the country's total expenditure on research and development. More significant, however, than this increase in Federal expenditure on research, in Dr. DuBridge's opinion, is the increase in non-Federal research expenditure, from 143 million dollars in 1930 to 1,740 millions in 1952 . Pointing out that it is almost impossible to distinguish rigidly between expenditure on military and non-military purposes, or even between research and development, Dr. DuBridge classified government activities according to five different management techniques commonly used : government agencies under civilian management ; government agencies under military management; government-owned institutions managed privately under contract; contracts for research or development services; and contracts or grants in support of research, usually to colleges or universities.

Dr. DuBridge does not believe that the United States Government is at present getting full value from its vast expenditure on research and development. He thinks that expenditure under the fifth category-research grants--is the most fruitful and valuable. In 1952 this, however, only amounted to about 71 million dollars; and he urged that this should be substantially increased. $\mathrm{He}$ is concerned also that 87 per cent of these funds come from the Atomic Energy Commission and the Department of Defence, whereas, in place of the 15 million dollars requested for basic research by the National Science Foundation, the Foundation has only received 3.25 millions in 1952 and 4.75 millions this year. As regards contracts for research services, Dr. DuBridge repeated the warning frequently given by others, that universities and colleges should be chary of accepting too heavy a load of such sponsored research lest their programmes of basic research be endangered.

The opinion was expressed by Dr. DuBridge that the most successful device for development of new ideas, equipment or techniques for the military services is that of government research centres under private management, such as the Los Alamos Scientific Laboratory operated for the Atomic Energy Commission by the University of California. He believes it desirable that any new research facilities-and as many existing ones as possible-should come under the private management contracts rather than military direction. Apart from proving grounds and acceptance or inspection centres, research centres for new military weapons would be more efficient under civilian direction. It is necessary, moreover, not only to give more attention to planning weapon development expenditure but also to consider problems of grand national strategy against the background of recent scientific and technical developments. For this reason, he suggested the appointment of an outstanding scientist or engineer as scientific adviser to the Defence Department, who might also serve as chairman of the Research and Development Board. The chairman of the Atomic Energy Commission should, in his opinion, be a member of the National Security Council, and that Council should be provided with a science advisory council with a full-time chairman.

\section{U.S. NATIONAL SCIENCE FOUNDATION}

\section{RESEARCH GRANTS}

$\mathrm{D}$

URING the year ended June 30, 1952*, the National Science Foundation made ninety-six grants totalling $1,073,975$ dollars for the support of basic research in the biological, medical, mathematical, physical and engineering sciences at fiftynine institutions in the United States. Research proposals totalling 13.3 million dollars were received, of which 38 per cent were declined, withdrawn or represented reductions in budgets of approved proposals, and 54 per cent are pending. New proposals submitted in 1953 will exceed the 1952 figure, but the limited Foundation funds for research have discouraged many competent investigators from submitting proposals. Those submitted to date have been marked to an unusual extent by originality in

* Sccond Annual Report of the National Science Foundation, Fiscal Year 1952. Pp. vili +77. (Washington, D.C.: Govt. Print. Office, 1953.) 30 cents. 